\section{Stereotactic and Functional Neurosurgery}

\title{
Long-Term Efficacy and Safety of Chronic Globus Pallidus Internus Stimulation in Different Types of Primary Dystonia
}

\author{
J.H. Mehrkens ${ }^{a} \quad$ K. Bötzel ${ }^{b} \quad$ U. Steude ${ }^{a}$ K. Zeitler ${ }^{c}$ A. Schnitzler ${ }^{d} \quad$ V. Sturm ${ }^{c}$ \\ J. Voges ${ }^{c, e}$ \\ ${ }^{a}$ Neurochirurgische und b ${ }^{b}$ eurologische Universitätsklinik, Klinikum Grosshadern, Ludwig-Maximilians-Universität \\ München, München, 'CKlinik für Stereotaxie und Funktionelle Neurochirurgie, Universität zu Köln, Köln, \\ ${ }^{\mathrm{d}}$ Neurologische Universitätsklinik, Heinrich-Heine-Universität Düsseldorf, Düsseldorf, und ${ }^{\text {e }}$ Stereotaktische \\ Neurochirurgie, Klinik für Neurologie II, Otto-von-Guericke-Universität Magdeburg, Magdeburg, Deutschland
}

\section{Key Words}

Deep brain stimulation - Dystonia $\cdot$ Globus pallidus internus $\cdot$ Long-term follow-up $\cdot$ Primary dystonia

\begin{abstract}
Background: Deep brain stimulation (DBS) of the globus pallidus internus (GPi) offers a very promising therapy for medically intractable dystonia. However, little is known about the long-term benefit and safety of this procedure. We therefore performed a retrospective long-term analysis of 18 patients (age 12-78 years) suffering from primary generalized (9), segmental (6) or focal (3) dystonia (minimum follow-up: 36 months). Methods: Outcome was assessed using the Burke-Fahn-Marsden (BFM) scores (generalized dystonia) and the Tsui score (focal/segmental dystonia). Follow-up ranged between 37 and 90 months (mean 60 months). $\boldsymbol{R e}$ sults: Patients with generalized dystonia showed a mean improvement in the BFM movement score of $39.4 \%$ (range 0 $68.8 \%$ ), $42.5 \%$ (range -16.0 to $81.3 \%$ ) and $46.8 \%$ (range -2.7 to $83.1 \%$ ) at the 3-and 12-month, and long-term follow-up, respectively. In focal/segmental dystonia, the mean reduction in the Tsui score was 36.8\% (range 0-100\%), 65.1\% (range $16.7-100 \%$ ) and $59.8 \%$ (range $16.7-100 \%$ ) at the $3-$ and 12 month, and long-term follow-up, respectively. Local infec-
\end{abstract}

tions were noted in 2 patients and hardware problems (electrode dislocation and breakage of the extension cable) in 1 patient. Conclusion: Our data showed Gpi-DBS to offer a very effective and safe therapy for different kinds of primary dystonia, with a significant long-term benefit in the majority of cases.

Copyright $\odot 2008$ S. Karger AG, Basel

\section{Introduction}

In most cases, primary dystonia with its different phenotypes is a severely disabling disease. Etiologically, a pathological process within the basal ganglia is supposed to be responsible for decreased motor cortex inhibition. Affected patients suffer from repetitive twisting movements or abnormal postures due to involuntary muscle contractions $[1,2]$. While conservative (medical) treatment options are extremely limited for generalized dystonia, in segmental dystonia, injections of botulinum toxin can alleviate symptoms for extended periods, but can also fail after repeated application $[3,4]$.

\section{J.H.M. and K.B. contributed equally to this study.}

\section{KARGER}

Fax +41613061234 E-Mail karger@karger.ch www.karger.com
(C) 2008 S. Karger AG, Basel

$1011-6125 / 09 / 0871-0008 \$ 26.00 / 0$

Accessible online at:

www.karger.com/sfn
Jan H. Mehrkens, MD, Department of Neurosurgery

Klinikum Grosshadern, Ludwig-Maximilians-Universität München

Marchioninistrasse 15, DE-81377 München (Germany)

Tel. +49897095 2580, Fax +49 8970955694

E-Mail jan.mehrkens@med.uni-muenchen.de 
For many years, stereotactic operations have been an alternative for patients with medically intractable dystonia. In the past, surgical treatment consisted mainly of stereotactically guided localized tissue destruction (e.g. thermocoagulation) inside thalamic motor nuclei or inside the globus pallidus internus (GPi). Although the motor symptoms improved following lesioning, there is also a considerable risk of adverse events and, moreover, the initial improvement can decrease over time [5-7]. In contrast to ablative stereotactic surgery, chronic stimulation can be safely used bilaterally. In addition, most stimulation-induced side effects and/or a decrease in the clinical benefit can be corrected by readjustment of stimulation parameters. During the last years, several study groups presented data on rather small patient cohorts using the GPi as target for deep brain stimulation (DBS) [8-11]. Only six recently published reports of larger series covered $>15$ patients [12-17]. Based on convincing solid data from the prospective controlled studies by Vidailhet et al. $[16,17]$ along with the results of the prospective randomized controlled two-arm study by Kupsch et al. [18], which showed the efficacy of bilateral GPi stimulation in comparison to sham stimulation in 40 patients with primary dystonia, evidence of the effectiveness of GPi-DBS in dystonia was accumulating. However, the mean follow-up of the cited studies was 22.3 months. Therefore, apart from the 3-year results from the controlled prospective series by Vidailhet et al. [17] or the very recently published data from a small case series (only 7 patients with primary dystonia) by Loher [19], little is known about the longterm efficacy and safety of chronic GPi stimulation in different types of dystonia or about pretreatment factors possibly predicting clinical outcome. To be able to address these problems in the present analysis, we pooled the immediate postoperative results and long-term follow-up data from two stereotactic centers analyzing 18 patients suffering from different types of primary dystonia with special focus on long-term efficacy and safety.

\section{Patients and Methods}

\section{Patient Population/Inclusion Criteria}

Patients with a history of severely disabling, medically intractable primary dystonia and a follow-up of $\geq 36$ months after implantation of GPi electrodes were considered eligible for the present analysis. Finally, a cohort of 18 (Munich: 12, Cologne: 6) consecutive patients ( 12 females, 6 males; mean age: 42.3 years, range 12-78 years) suffering from primary generalized (9), segmental (6) and focal (3) dystonia treated with GPi-DBS between February 1999 and February 2002 were included. The reference point of this study was the date of implantation. All patients who suffered from
Table 1. Characteristics of the study population

\begin{tabular}{rllllll}
\hline ID & $\begin{array}{l}\text { Age at } \\
\text { Surgery } \\
\text { years }\end{array}$ & Sex & $\begin{array}{l}\text { Duration } \\
\text { of disease } \\
\text { years }\end{array}$ & $\begin{array}{l}\text { DYT1 } \\
\text { muta- } \\
\text { tion }\end{array}$ & $\begin{array}{l}\text { Distribution } \\
\text { of dystonia }\end{array}$ & $\begin{array}{l}\text { Follow- } \\
\text { up } \\
\text { months }\end{array}$ \\
\hline 1 & 45 & f & 4.3 & no & generalized & 67.0 \\
2 & 35 & m & 15.6 & no & generalized & 70.0 \\
3 & 23 & f & 19.9 & no & generalized & 54.0 \\
4 & 44 & f & 37.1 & no & generalized & 51.0 \\
5 & 24 & f & 18.0 & no & generalized & 50.0 \\
6 & 53 & f & 40.7 & yes & generalized & 45.0 \\
7 & 20 & f & 13.0 & yes & generalized & 90.0 \\
8 & 12 & m & 4.0 & no & generalized & 68.0 \\
9 & 14 & f & 2.0 & yes & generalized & 59.0 \\
10 & 61 & m & 19.0 & no & segmental & 75.0 \\
11 & 78 & f & 6.0 & NA & segmental & 67.0 \\
12 & 44 & m & 4.0 & NA & segmental & 48.0 \\
13 & 51 & m & 8.0 & NA & segmental & 81.0 \\
14 & 44 & m & 8.0 & NA & segmental & 41.0 \\
15 & 45 & f & 19.0 & NA & segmental & 37.0 \\
16 & 58 & f & 15.0 & NA & focal & 73.0 \\
17 & 70 & f & 31.0 & NA & focal & 54.0 \\
18 & 41 & m & 9.0 & NA & focal & 50.0 \\
\hline & & & & & &
\end{tabular}

ID $=$ Patient identification number NA $=$ not assessed.

${ }^{1}$ Preoperatively.

cervical dystonia had initially been successfully treated with botulinum toxin. DBS was offered when the positive effect of the injections weakened, most probably due to an immune response against this substance. Patients with generalized dystonia were screened for a DYT1 mutation. Patients' characteristics are summarized in table 1. The last follow-up was performed in August 2006.

\section{Neurosurgical Technique/Implants}

Bilateral pallidal electrode implantation (model 3387; Medtronic, Minneapolis, Minn., USA) with intraoperative macroelectrode testing was either performed under propofol (12 patients) or local (6 patients) anesthesia with MRI-guided stereotaxy using a modified Leksell/Lerch system (Munich) or ventriculography combined with 3D stereotactic CT and MR imaging and a modified Riechert-Mundinger stereotactic head ring (Cologne).

The methodology applied for imaging, treatment planning and implantation has been published in detail elsewhere $[11,20]$. The preliminary target within the GPi was defined as follows: $3 \mathrm{~mm}$ anterior to the AC-PC midpoint, $18-22 \mathrm{~mm}$ lateral to the midline and 3-6 mm below the IC plane [21]. The standard target coordinates were adjusted based on individual anatomical landmarks (third ventricle/optical tract). Intraoperative microelectrode recordings were not performed in this study. Permanent implantation of the stimulation system into a subcutaneous infraclavicular pouch (IPG, model, Soletra or Kinetra; Medtronic) was performed either after 3-5 days of testing for side effects with an external pulse generator system using percutaneous extensions (12 patients, Munich) or immediately after implantation of the 
Table 2. Stimulation parameters (means $\pm \mathrm{SD}$ )

\begin{tabular}{|c|c|c|c|c|c|c|}
\hline & \multicolumn{2}{|c|}{ Amplitude, V } & \multicolumn{2}{|c|}{ Pulse width, $\mu$ s } & \multicolumn{2}{|c|}{ Frequency, $\mathrm{Hz}$} \\
\hline & left & right & left & right & left & right \\
\hline Discharge & $3.0 \pm 0.5$ & $2.7 \pm 0.6$ & $111.8 \pm 31.7$ & $111.8 \pm 25.8$ & $131.2 \pm 7.8$ & $132.7 \pm 13.7$ \\
\hline 3-month follow up & $3.0 \pm 0.3$ & $3.1 \pm 0.7$ & $128.5 \pm 39.2$ & $128.8 \pm 27.6$ & $135.9 \pm 14.2$ & $136.2 \pm 17.5$ \\
\hline 12-month follow-up & $3.1 \pm 0.8$ & $3.2 \pm 0.4$ & $154.3 \pm 46.9$ & $147.9 \pm 50.56$ & $133.2 \pm 8.7$ & $137.1 \pm 16.3$ \\
\hline 36-month follow-up & $3.2 \pm 0.8$ & $3.4 \pm 0.6$ & $144.3 \pm 42.9$ & $141.2 \pm 41.9$ & $134.3 \pm 10.9$ & $139.3 \pm 17.9$ \\
\hline Last follow-up ( $>36$ months) & $3.2 \pm 0.8$ & $3.3 \pm 0.6$ & $137.7 \pm 43.8$ & $134.1 \pm 45.2$ & $139.1 \pm 15.8$ & $140.6 \pm 18.8$ \\
\hline
\end{tabular}

deep brain electrodes (6 patients, Cologne). Prophylactic systemic antibiotic treatment (cefuroxime, $3 \times 1.5 \mathrm{~g}$ /day) was administered to all patients perioperatively and for at least 1 week postoperatively. Hospitalization ranged from 14 to 24 days.

\section{Stimulation/Parameters}

The most distal electrode contact of the quadripolar electrode which caused no side effects when activated was chosen for continuous monopolar stimulation with comparably high intensity from the beginning (mean $80 \mu \mathrm{A}$ ). Thereafter, the amplitude was stepwise increased over several days to determine for each patient individually a level which gained maximum clinical response with no or minimal side effects (e.g. phosphenes, motor symptoms and speech disturbance). Stimulation parameters are summarized in table 2.

\section{Patient Evaluation}

Clinical outcome was assessed preoperatively, at discharge from hospital (mean 10 days after initial programming), and 3, 6 and 12 months postoperatively and then annually) using the Burke-Fahn-Marsden (BFM) dystonia rating scale (motor and disability) for patients with generalized dystonia and the Tsui rating scale for patients with focal or segmental dystonia [22, 23]. The Tsui score consists of several subscores assessing the amplitude and duration of sustained movements, shoulder elevation and tremor. Due to its detailed subscores, we considered this score to be best suited to evaluate torticollis and segmental dystonia.

Twelve patients received an immediate postoperative MRI to control electrode position. In 6 patients, the coordinates of the final electrode position were taken from intraoperative stereotactic plain X-ray images. Finally, placement of the electrode (active contact) inside the GPi was verified using the individual customized planning software for co-registration with the treatment planning MRI (and the Schaltenbrand brain atlas [24]). The exact position of all active contacts was referenced to the AC-PC midpoint (Matlab 7.1; MathWorks, Natick, Mass., USA).

\section{Statistical Methods}

The Wilcoxon matched-pair signed-rank test was applied to compare changes in the rating scale scores pre- and postoperatively [response at discharge, 3 and 12 months, and long-term follow-up (>36 months)]. Student's t test was used to analyze differences between population subgroups. A correlation analysis using the Spearman correlation coefficient along with linear regression analysis was used to test for pretreatment prognosticators of long- term outcome (at 36 months) as well as correlation between electrode localization and outcome. $\mathrm{p}<0.05$ was considered statistically significant. Statistical analyses were performed using the SPSS 14.0 and 16.0 software (SPSS, Chicago, Ill., USA).

\section{Results}

\section{Clinical Patient Outcome}

In summary, most of our patients demonstrated a very rapid response to DBS with significant improvement in their symptoms already during the 1st postoperative week. Improvement was $>50 \%$ in $4 / 9$ patients with generalized and in 5/9 patients with focal/segmental dystonia. The follow-up of the entire patient group ranged from 37 to 90 months (mean 60 months).

Generalized Dystonia. Patients with generalized dystonia were severely affected with a high mean preoperative BFM movement and disability score of 57 (median 55, range 27-106) and 14.4 (median 14, range 7-26), respectively. At discharge from hospital, there were mean improvements in the BFM movement score of $39.4 \%$ (median 38, range $0-68.8 \%$ ) and in the BFM disability score of $29.9 \%$ (median 29, range 7.1-71.4\%). After 3 months, both scores (movement and disability) further improved in 2 patients. In comparison to the immediate postoperative status, the values remained stable in 5 individuals and had worsened in 2 patients. Intermediate analysis at 12 months revealed mean improvements in the BMF movement and disability scores of 42.5 (median 63, range -16.0 to $81.3 \%$ ) and $37.9 \%$ (median 30 , range $7.1-73.3 \%$ ). These improvements remained constant at the longterm-follow up at 36 months and at the last follow-up in 5 , severely reduced in 2 and moderately reduced in 2 patients (fig. 1,2). The mean percent improvements in comparison to the preoperative status together with the statistical values are listed in table 3. Individual scores at follow-up are listed in table 4. 
1

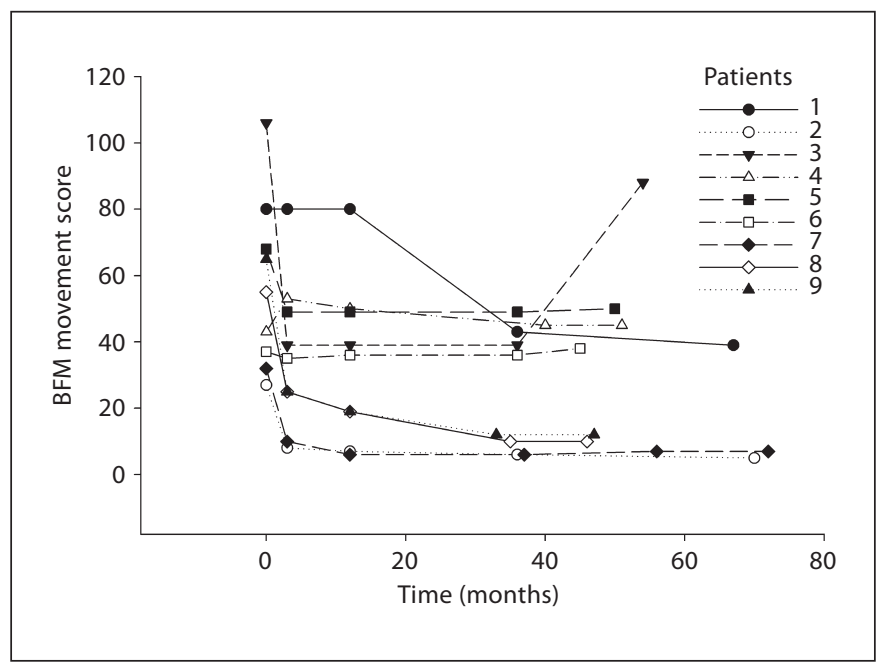

2

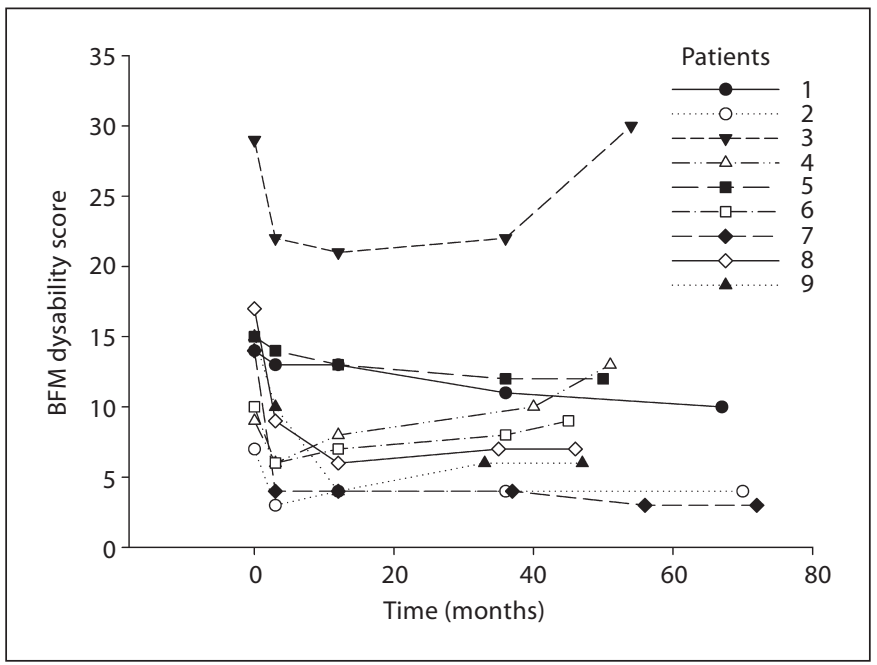

Fig. 1, 2. Graph showing the course of BFM movement (1) and BFM disability scores (2) for the 9 patients with generalized dystonia in the long-term follow-up. The reference point was the date of electrode implantation.

Table 3. BFM dystonia rating scale in generalized dystonia

\begin{tabular}{|c|c|c|c|c|c|}
\hline & Preoperatively & 3-month FU & 12-month FU & 36-month FU & Last FU \\
\hline \multicolumn{6}{|c|}{ BFM dystonia rating scale } \\
\hline Movement score & $57.0 \pm 25.6$ & $36.0 \pm 22.7$ & $33.9 \pm 24.0$ & $27.6 \pm 18.4$ & $32.7 \pm 27.3$ \\
\hline Disability score & $14.4 \pm 6.4$ & $9.7 \pm 6.0$ & $8.9 \pm 5.8$ & $9.4 \pm 22.0$ & $10.4 \pm 8.1$ \\
\hline \multicolumn{6}{|c|}{ Change to preoperatively } \\
\hline \multicolumn{6}{|c|}{ Movement } \\
\hline Change, \% & & $36.8 \pm 34.9$ & $42.5 \pm 37.2$ & $50.3 \pm 35.7$ & $46.8 \pm 36.5$ \\
\hline $\mathrm{p}$ value & & 0.008 & 0.008 & 0.008 & 0.01 \\
\hline \multicolumn{6}{|l|}{ Disability } \\
\hline Change, $\%$ & & $35.6 \pm 21.5$ & $37.9 \pm 26.4$ & $32.9 \pm 27.2$ & $26.7 \pm 37.7$ \\
\hline $\mathrm{p}$ value & & 0.004 & 0.004 & 0.004 & 0.008 \\
\hline
\end{tabular}

Focal/Segmental Dystonia (Cervical Dystonia). The overall mean reductions in the Tsui score were $36.8 \%$ (range $0-100 \%$ ) at 3 months, $65.1 \%$ (range $16.7-100 \%$ ) at 12 months, $61.5 \%$ at 36 months (range 16.7-100\%) and $59.8 \%$ (range 16.7-100\%) at the last follow-up. As shown in figure 3 , outcome in patients displayed a large variability, ranging from complete resolution of symptoms in 2 cases with pure torticollis (patients 16 and 18) to only very moderate long-term improvement in another $3 \mathrm{pa}$ tients (patients 12, 14 and 17). The mean percent improvements in comparison to the preoperative status together with the statistical values are listed in table 5. Individual scores at follow-up are listed in table 4.
Statistical Analysis. At the 3-and 12-month, and at the long-term follow-ups ( 36 months and $>36$ months, with a mean of 60 months), mean improvements were significantly different compared with the preoperative status (Wilcoxon's matched-pair signed-rank test) for both groups, i.e. general dystonia (motor and disability score, table 3) and focal/segmental dystonia (table 5). There was no statistically significant difference in the long-term benefit between the 36-month and the last ('open-label' longterm) follow-up. In generalized dystonia, correlation and linear regression analysis showed age at surgery $\left(\mathrm{r}^{2}=0.593\right.$, significance 0.004) and duration of disease prior to DBS $\left(\mathrm{r}^{2}=0.712\right.$, significance 0.004$)$ to be significant predictors 
Table 4. Individual outcome scores

\begin{tabular}{|c|c|c|c|c|c|c|c|c|}
\hline ID & Dystonia & Assessment & $\mathrm{PO}$ & 1 week & 3 months & 12 months & 36 months & Last FU \\
\hline \multirow[t]{2}{*}{1} & \multirow[t]{2}{*}{ generalized } & BFM-M & 80 & 80 & 80 & 80 & 43 & 39 (67 months) \\
\hline & & BFM-D & 14 & 13 & 13 & 13 & 11 & 10 \\
\hline \multirow[t]{2}{*}{2} & \multirow[t]{2}{*}{ generalized } & BFM-M & 27 & 12 & 8 & 7 & 6 & 5 (70 months) \\
\hline & & BFM-D & 7 & 5 & 3 & 4 & 4 & 4 \\
\hline \multirow[t]{2}{*}{3} & \multirow[t]{2}{*}{ generalized } & BFM-M & 106 & 39 & 39 & 39 & 39 & 88 (54 months) \\
\hline & & BFM-D & 29 & 22 & 22 & 21 & 22 & 30 \\
\hline \multirow[t]{2}{*}{4} & \multirow[t]{2}{*}{ generalized } & BFM-M & 43 & 33 & 53 & 50 & 45 & 45 (51 months) \\
\hline & & BFM-D & 9 & 7 & 6 & 8 & 10 & 13 \\
\hline \multirow[t]{2}{*}{5} & \multirow[t]{2}{*}{ generalized } & BFM-M & 68 & 42 & 49 & 49 & 49 & 50 (50 months) \\
\hline & & BFM-D & 15 & 13 & 14 & 13 & 12 & 12 \\
\hline \multirow[t]{2}{*}{6} & \multirow[t]{2}{*}{ generalized } & BFM-M & 37 & 35 & 35 & 36 & 36 & 38 (45 months) \\
\hline & & BFM-D & 10 & 6 & 6 & 7 & 8 & 9 \\
\hline \multirow[t]{2}{*}{7} & \multirow[t]{2}{*}{ generalized } & BFM-M & 32 & 10 & 10 & 6 & 6 & 7 (90 months) \\
\hline & & BFM-D & 14 & 4 & 4 & 4 & 4 & 3 \\
\hline \multirow[t]{2}{*}{8} & \multirow[t]{2}{*}{ generalized } & BFM-M & 55 & 35 & 25 & 19 & 10 & 10 (68 months) \\
\hline & & BFM-D & 17 & 12 & 9 & 6 & 7 & 7 \\
\hline \multirow[t]{2}{*}{9} & \multirow[t]{2}{*}{ generalized } & BFM-M & 65 & 25 & 25 & 19 & 12 & 12 (59 months) \\
\hline & & BFM-D & 15 & 10 & 10 & 4 & 6 & 6 \\
\hline 10 & segmental & Tsui & 13 & 13 & 13 & 5 & 6 & 8 (75 months) \\
\hline 11 & segmental & Tsui & 13 & 13 & 13 & 6 & 4 & 4 (67 months) \\
\hline 12 & segmental & Tsui & 24 & 6 & 6 & 6 & 18 & 18 (48 months) \\
\hline 13 & segmental & Tsui & 14 & 0 & 4 & 2 & 2 & 2 (81 months) \\
\hline 14 & segmental & Tsui & 17 & 14 & 12 & 13 & 13 & 13 (41 months) \\
\hline 15 & segmental & Tsui & 10 & 5 & 4 & 3 & 2 & 2 (37 months) \\
\hline 16 & focal & Tsui & 10 & 2 & 1 & 0 & 0 & 0 (73 months) \\
\hline 17 & focal & Tsui & 12 & 12 & 11 & 10 & 10 & 10 (54 months) \\
\hline 18 & focal & Tsui & 6 & 2 & 0 & 0 & 0 & 0 (50 months) \\
\hline
\end{tabular}

Individual outcome scores applying either the BFM score in generalized dystonia or the Tsui-score in focal/segmental dystonia.

The 36-month follow-up was performed within a range of 32-40 months. ID = Patient identification number; $\mathrm{PO}=$ preoperatively; FU = follow-up; BFM-M = BFM movement; BFM-D = BFM disability.

Table 5. Tsui rating scale in patients with focal and segmental dystonia

\begin{tabular}{|c|c|c|c|c|c|}
\hline & Preoperatively & 3-month FU & 12-month FU & 36-month FU & $\begin{array}{l}\text { Last FU } \\
\text { (>36 months) }\end{array}$ \\
\hline $\begin{array}{l}\text { Tsui score } \\
\text { Change to preoperatively }\end{array}$ & $13.2 \pm 5.1$ & $5.2 \pm 5.2$ & $5.0 \pm 4.4$ & $6.1 \pm 6.3$ & $6.3 \pm 6.3$ \\
\hline $\begin{array}{l}\text { Change, } \% \\
\text { p value }\end{array}$ & & $\begin{array}{l}36.8 \pm 39.4 \\
0.01\end{array}$ & $\begin{array}{l}65.1 \pm 30.0 \\
0.003\end{array}$ & $\begin{array}{l}61.5 \pm 33.1 \\
0.003\end{array}$ & $\begin{array}{l}59.8 \pm 34.0 \\
0.003\end{array}$ \\
\hline
\end{tabular}

Means \pm SD. FU = Follow-up.

of long-term outcome at 36 months, e.g. patients with a disease duration prior to DBS $<15$ years ( $4 / 9$ patients) had a statistically significantly better long-term outcome (mean improvement in the BFM movement score of 73.6 vs. $25.4 \%, p=0.03$, Student's t test). For focal and segmental dystonia, no statistically significant correlation was found (factors tested: age at surgery, duration of disease prior to DBS, severity of symptoms and DYT-1 carrier status).

Electrode Position. Postoperative MRI (12/18 patients) or stereotactic X-ray (6/18 patients) confirmed the correct 


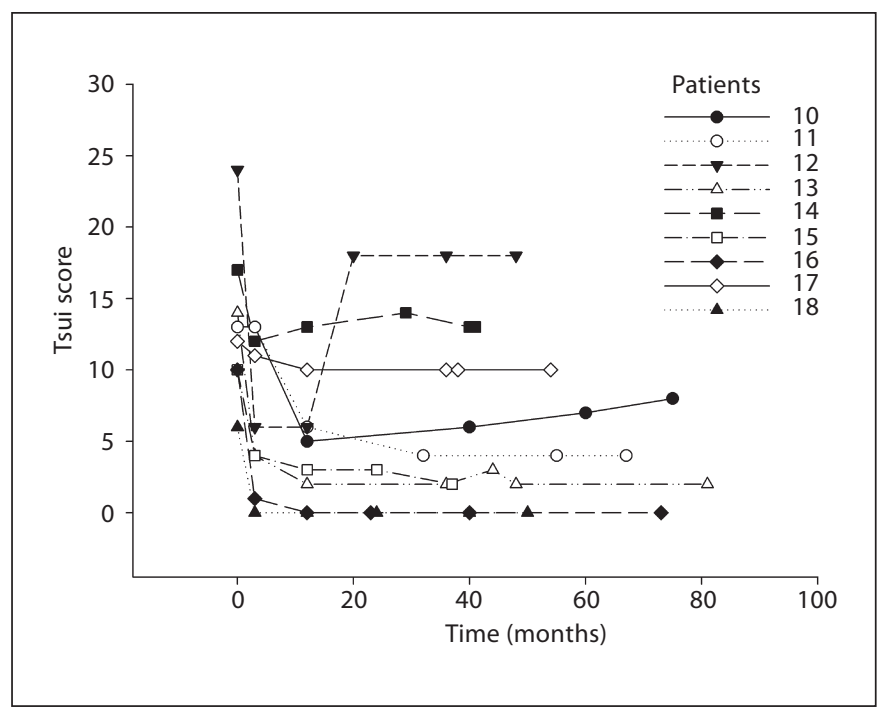

Fig. 3. Graph showing the course of Tsui scores for the 9 patients with focal/segmental dystonia in the long-term follow-up. The reference point was the date of electrode implantation.

placement of the electrodes within the (posteroventral) GPi. Mean stereotactic coordinates of the active electrode contacts were: (1) left hemisphere: $3.91 \mathrm{~mm}$ (range 0.0-7.2 $\mathrm{mm}$ ) anterior to the midcommisural point, $20.4 \mathrm{~mm}$ (range 14.6-25.2 mm) lateral to the midline of the 3rd ventricle and $1.7 \mathrm{~mm}$ (range $0-9.1 \mathrm{~mm}$ ) below the AC-PC plane, and (2) right hemisphere: $4.2 \mathrm{~mm}$ (range 0.0-7.4 $\mathrm{mm}$ ) anterior to the midcommisural point, $21.0 \mathrm{~mm}$ (range 17.6-26.0 mm) lateral to the midline of the 3rd ventricle and $1.8 \mathrm{~mm}$ (range $0-9.1 \mathrm{~mm}$ ) below the AC-PC plane.

The 3 patients with the most anteriorly positioned electrodes had no (patients 4 and 6) or only moderate (patient 5) long-term success. There was neither a statistically significant correlation between electrode position and outcome in patients with extremely worse or better outcome nor in the subgroups with an outcome $<$ or $>50 \%$ (fig. 4 ).

\section{Stimulation Parameters}

Parameters at discharge and at follow-up are given in table 2. The initial amplitude settings (on discharge) had to be increased in all patients during follow-up in order to further optimize the control of involuntary movements.

Pulse Generator Replacement. The mean interval for replacement was 43.4 (17 patients, range 31-59 months) and 38.3 months (5 patients, range $32-48$ months) for the first and second replacement, respectively. There was no statistically significant difference in time to replacement between the different types of IPG (Itrel II, Soletra or Kinetra).

\section{Complications}

Perioperative Mortality and Morbidity. Despite 1 case with a subcutaneous hematoma at the site of the extension cable (complete recovery without permanent deficits), there was no other directly surgery-related morbidity or mortality in this patient series.

Infections. Local infections were encountered in 2 patients: One patient (patient 7) presented with local infection at the burr hole necessitating removal of the left DBS electrode 14 days after the primary procedure. Re-implantation was performed 3 months later without complications, and the same excellent stimulation result as before was achieved. Another patient (patient 13) suffered from a local infection at the right infraclavicular IPG 6 weeks after IPG replacement in an outside institution (46 months after primary implantation) requiring IPG explantation. Re-implantation was performed 6 weeks later without further sequelae.

Long-Term Complications/Side Effects. One young female patient suffering from generalized dystonia (patient 9) with an excellent clinical course and initially significant improvement due to GPi-DBS developed (with a delay of 3 years) extreme psychosocial behavioral abnormalities (aggressiveness/uncooperativeness) necessitating intensive psychological treatment. With adequate psychological support, her clinical status stabilized. Depending on stimulation intensity, mild speech disturbances occurred in 2 patients. Due to the otherwise excellent clinical response, this mild impairment was well accepted. An accidental inactivation of the IPGs (i.e. an airport metal detector and a professional kitchen machine) with almost immediate re-occurrence of dystonic symptoms was observed in 2 patients.

Hardware Complications. In 1 patient (patient 9), we documented loosening of the burr hole cap with consecutive electrode dislocation (39 months postoperatively) and in the later course (58 months postoperatively) breakage of the extension cable. Both events were accompanied by a loss of stimulation and consecutive severe worsening of clinical symptoms. Complete restitution could be achieved in either event by immediate operative revision (i.e. revision of the DBS electrode and the extension cable, respectively). 


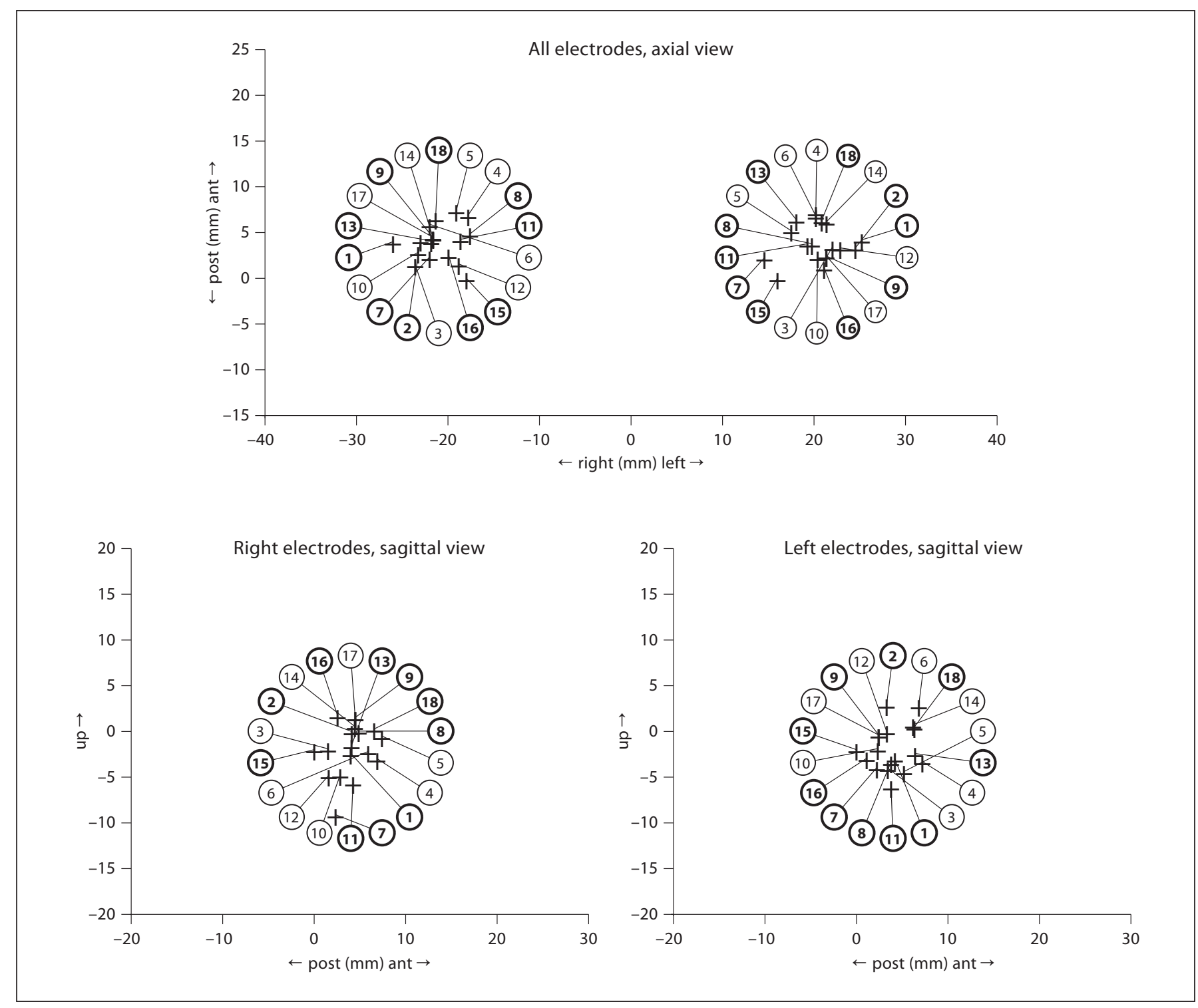

Fig. 4. Graph showing localization of active contacts for all electrodes with respect to AC-PC coordinates. Numbers in circles refer to the patient identification numbers also given in tables 1 and 4 . Bold circles indicate patients with a long-term benefit $>50 \%$. No significant correlation between outcome and electrode position was detected.

\section{Discussion}

High-frequency DBS with neuromodulatory instead of destructive effects, hence being reversibly and individually adjustable, and with its high therapeutic efficacy has replaced ablative procedures like pallidotomy or thalamotomy during the last 10 years. This development was paralleled by an increasing acceptance of stereotactic neurosurgery for the treatment of movement disorders.[8-15, 25]. Moreover, prospective multicenter trials with a controlled (randomized) protocol proved the efficacy of DBS for patients with generalized dystonia [1618].

The present analysis addressing postoperative and long-term (mean follow-up: 60 months) clinical results in a cohort of 18 patients covered different types of primary dystonia, including the largest long-term series of patients suffering from focal/segmental dystonia to date. Clinical symptoms improved in both patient groups significantly. In detail, at the 36-month and at the last fol- 
low-up examination (36-90 months), the average clinical benefit expressed as a reduction in the BMF movement and disability scores were 50/33 and $47 / 27 \%$, respectively, in the group with generalized dystonia and 62 and $60 \%$ in patients with focal/segmental dystonia who were assessed using the Tsui scale.

In contrast to most previous reports, in the present study, we documented for a reasonably high number of patients $(9 / 18)$ a significant improvement in symptoms (improvement $>50 \%$ ) already during the 1st postoperative week [10, 14-16]. In agreement with Kupsch et al. [18], these early beneficial effects became visible in mobile dystonia rather than in fixed dystonic postures. However, this is observation cannot be generalized since there was no statistically sound proof. For reasons of clinical practicability, we applied two different score systems complicating the direct comparison of patients with general dystonia and those with predominant torticollis in the segmental/focal group. In the latter cohort, the Tsui score, a scoring system for torticollis widely used by European groups, had been applied, since features of focal/segmental dystonia are assessed in more detail [23]. As a consequence, particular aspects of the results will be discussed individually for both patient cohorts.

\section{Generalized Dystonia}

The present analysis showed that the significant improvements in BFM scores 12 months after the start of DBS (movement: $46.8 \pm 36.5 \%$ and disability: $26.7 \pm$ $37.7 \%$ ) were maintained during the long-term follow-up (maximum follow-up time: 72 months, mean follow-up time: 59.6 months) in 5/9 patients, with a mean motor improvement of $50.3 \%$ at the 36 -month follow-up and excellent results in 3 young patients (age at surgery 12, 13 and 20 years), with an improvement of 81,82 and $82 \%$, respectively. These results compare very well to the prospective short- and long-term outcome reported by Vidailhet et al. $[16,17]$ who also found improvements $>75 \%$ in (only) one third of their patients. However, in 3 patients with significant initial benefit, we registered moderate (patients 4-6) and in 1 patient (patient 3 ) substantial worsening in the positive stimulation effect over time (fig. 1, 2; table 3, 4). In this group of patients with a history of dystonia prior to treatment of $>15$ years, longterm outcome was found to be statistically significantly worse than in individuals with a shorter history of dystonia (mean improvement in the BFM movement score 25.4 vs. $73.6 \%, p=0.03$ ). Moreover, in contrast to other studies, correlation and linear regression analysis revealed age at surgery and duration of disease prior DBS to be statistically significant predictors for long-term outcome (at 36 months) in our series [18]. In concordance to the results of the randomized controlled series by Kupsch et al. [18], there was also no statistical difference in outcome between the patients with or without DYTI mutation in our patient cohort.

These observations might indicate the necessity of early neurosurgical intervention to achieve an optimal clinical outcome. Although the results have to be confirmed in a prospective study, early treatment seems to be even more important in pediatric/juvenile patients to prevent irreversible impairment of motor function (muscle, joint and bone destruction/deformity).

Further studies in patients with insufficient or decreasing response have to elucidate the benefit of low-frequency stimulation $(60 \mathrm{~Hz})$, yielding significant improvement in $89 \%$ after 12 months in a study by Alterman et al. [26], or targeting of the nucleus subthalmicus, an alternative approach with very promising results $[27,28]$. However, both concepts seem very interesting (with obvious advantages: e.g. a longer battery life) and might be applied in our institution in the future, especially in patients with inappropriate response to 'standard' high-frequency Gpi-DBS.

\section{Electrode Position}

Despite the fact that the 3 patients with the most anteriorly positioned electrodes had no (patients 4 and 6) or only moderate (patient 5) long-term improvement (generalized dystonia), there was neither a statistically significant correlation in electrode position and outcome in patients with extremely worse or better outcome nor in the subgroups with an outcome $<$ or $>50 \%$ (fig. 4). In general, position of the active contacts within the GPi was in agreement with previously published results [13].

\section{Segmental/Focal Dystonia}

In accordance with other studies, outcome in patients with segmental/focal dystonia varied largely during longterm follow-up, which is reflected by the great standard deviation in documented scores (6.3 at the last follow-up) $[8,14]$. There was neither a significantly higher degree of fixed posture in the patients with a less favorable response (as documented by the Tsui subscores, data not shown) nor could statistically significant predictors for outcome be detected. The best effect was observed for cervical dystonic symptoms (2 patients with pure torticollis showed a stable complete relief of their symptoms) as well as for the Meige syndrome. In our series, results were comparably worse in patients with dystonic movements in the 
shoulder/arm region and/or in patients with predominating clonic-dystonic symptoms (e.g. dystonic tremor). However, bearing in mind that other groups applied voltages as high as $5.0 \mathrm{~V}$, generally stating that GPi-DBS is less effective in 'complex' segmental dystonia may be misleading, since the voltages used in our patients $(<3.6 \mathrm{~V})$ may have been too low to observe a significant benefit $[19$, 29]. Despite these limitations, the overall improvement remained stable if referred to the total follow-up time (maximum 81 months) and was statistically significant compared with baseline values.

These results support the important role of GPi-DBS in patients with cervical dystonia, confirming previous data in patients with a significantly shorter follow-up [18, 29-31].

\section{Complications}

In contrast to other reports covering a number of patients comparable to our series, stereotactic implantation of the brain electrodes did not give rise to mortality or severe morbidity (e.g. symptomatic intracerebral hemorrhage or new neurological sequelae) [32]. Also, the rate of other perioperative adverse events was low (1/18 patients, $6 \%)$ in our patients. The comparably high number of patients (4/18 patients, 22.2\%) who presented with implantrelated (long-term) complications (local infections, electrode dislocation or peripheral cable breakage) is in accordance with previously published reports addressing this particular problem $[18,33]$. Of note, the two infections encountered were not long-term complications. In the patient requiring electrode explantation, the local in- fection at the burr hole occurred 14 days after implantation and after 10 days of externalization of the electrodes. In the patient with IPG infection, infection manifested at the long-term follow-up (46 months after initial surgery); however, the patient had undergone IPG replacement only 6 weeks prior to manifestation of the infection.

With the exception of temporary aggressive behavior documented in a young female suffering from generalized dystonia, who responded very well to adequate psychological treatment, other mood disturbances were not observed (e.g. a tendency to depressive or even suicidal behavior), being in contrast to others [34].

The mild speech disturbances (dysarthria) noted in 2 cases were not clinically significant and were well tolerated, because of the excellent clinical improvement in their dystonic symptoms.

\section{Conclusion}

GPi-DBS is safe in patients suffering from primary generalized, segmental or focal dystonia with excellent short-term stimulation effects as already published. In the present analysis, long-term results were also excellent in 3 young patients with generalized dystonia and 2 patients with torticollis. Patients with segmental dystonia showed marked but incomplete relief of their symptoms. Early treatment seems to be crucial to achieve optimal therapeutic benefit in patients with generalized dystonia.

\section{References}

1 Fahn S, Bressman SB, Marsden CD: Classification of dystonia. Adv Neurol 1998;78:110.

2 Klein C, Ozelius LJ: Dystonia: clinical features, genetics, and treatment. Curr Opin Neurol 2002;15:491-497.

3 Dressler D: Clinical presentation and management of antibody-induced failure of botulinum toxin therapy. Mov Disord 2004; 19(suppl 8):S92-S100.

4 Balash Y, Giladi N: Efficacy of pharmacological treatment of dystonia: evidence-based review including meta-analysis of the effect of botulinum toxin and other cure options. Eur J Neurol 2004;11:361-370.

5 Ondo WG, Desaloms JM, Jankovic J, Grossman RG: Pallidotomy for generalized dystonia. Mov Disord 1998;13:693-698.
6 Vitek JL, Bakay RA: The role of pallidotomy in Parkinson's disease and dystonia. Curr Opin Neurol 1997;10:332-339.

7 Gros C, Frerebeau P, Perez-Dominguez E, Bazin M, Privat JM: Long term results of stereotaxic surgery for infantile dystonia and dyskinesia. Neurochirurgia (Stuttg) 1976;19: 171-178.

8 Krauss JK, Pohle T, Weber S, Ozdoba C, Burgunder JM: Bilateral stimulation of globus pallidus internus for treatment of cervical dystonia. Lancet 1999;354:837-838.

9 Tronnier VM, Fogel W: Pallidal stimulation for generalized dystonia: report of three cases. J Neurosurg 2000;92:453-456.
10 Coubes P, Roubertie A, Vayssiere N, Hemm S, Echenne B: Treatment of DYT1-generalised dystonia by stimulation of the internal globus pallidus. Lancet 2000;355:22202221.

11 Bereznai B, Steude U, Seelos K, Botzel K: Chronic high-frequency globus pallidus internus stimulation in different types of dystonia: a clinical, video, and MRI report of six patients presenting with segmental, cervical, and generalized dystonia. Mov Disord 2002; 17:138-144.

12 Yianni J, Bain P, Giladi N, Auca M, Gregory R, Joint C, Nandi D, Stein J, Scott R, Aziz T: Globus pallidus internus deep brain stimulation for dystonic conditions: a prospective audit. Mov Disord 2003;18:436-442. 
13 Starr PA, Turner RS, Rau G, Lindsey N, Heath S, Volz M, Ostrem JL, Marks WJ Jr: Microelectrode-guided implantation of deep brain stimulators into the globus pallidus internus for dystonia: techniques, electrode locations, and outcomes. J Neurosurg 2006; 104:488-501.

14 Krause M, Fogel W, Kloss M, Rasche D, Volkmann J, Tronnier V: Pallidal stimulation for dystonia. Neurosurgery 2004;55: 1361-1370.

15 Coubes P, Cif L, El Fertit H, Hemm S, Vayssiere N, Serrat S, Picot MC, Tuffery S, Claustres M, Echenne B, Frerebeau P: Electrical stimulation of the globus pallidus internus in patients with primary generalized dystonia: long-term results. J Neurosurg 2004;101: 189-194.

16 Vidailhet M, Vercueil L, Houeto JL, Krystkowiak P, Benabid AL, Cornu P, Lagrange C, Tézenas du Montcel S, Dormont D, Grand S, Blond S, Detante O, Pillon B, Ardouin C, Agid Y, Destée A, Pollak P, French Stimulation du Pallidum Interne dans la Dystonie (SPIDY) Study Group: Bilateral deep-brain stimulation of the globus pallidus in primary generalized dystonia. N Engl J Med 2005; 352:459-467.

17 Vidailhet M, Vercueil L, Houeto JL, Krystkowiak P, Lagrange C, Yelnik J, Bardinet E, Benabid AL, Navarro S, Dormont D, Grand S, Blond S, Ardouin C, Pillon B, Dujardin K, Hahn-Barma V, Agid Y, Destée A, Pollak P, French SPIDY Study Group: Bilateral, pallidal, deep-brain stimulation in primary generalised dystonia: a prospective 3 year follow-up study. Lancet Neurol 2007;6:223229.
18 Kupsch A, Benecke R, Muller J, Trottenberg T, Schneider GH, Poewe W, Eisner W, Wolters A, Muller JU, Deuschl G, Pinsker MO, Skogseid IM, Roeste GK, Vollmer-Haase J, Brentrup A, Krause M, Tronnier V, Schnitzler A, Voges J, Nikkhah G, Vesper J, Naumann M, Volkmann J, Deep-Brain Stimulation for Dystonia Study Group: Pallidal deep-brain stimulation in primary generalized or segmental dystonia. N Engl J Med 2006 355:1978-1990.

19 Loher TJ, Capelle HH, Kaelin-Lang A, Weber S, Weigel R, Burgunder JM, Krauss JK: Deep brain stimulation for dystonia: outcome at long-term follow-up. J Neurol 2008; 255:881-884.

20 Voges J, Volkmann J, Allert N, Lehrke R, Koulousakis A, Freund HJ, Sturm V: Bilateral high-frequency stimulation in the subthalamic nucleus for the treatment of Parkinson's disease: correlation of therapeutic effect with anatomical electrode position. J Neurosurg 2002;96:269-279.

21 Laitinen LV, Bergenheim AT, Hariz MI: Leksell's posteroventral pallidotomy in the treatment of Parkinson's disease. J Neurosurg 1992;76:53-61.

22 Burke RE, Fahn S, Marsden CD, Bressman SB, Moskowitz C, Friedman J: Validity and reliability of a rating scale for the primary torsion dystonias. Neurology 1985;35:7377.

23 Tsui JK, Eisen A, Stoessel AJ, Calne S, Calne DB: Double-blind study of botulinum toxin in spasmodic torticollis. Lancet 1986;ii:245247.

24 Schaltenbrand G, Wahren W: Atlas for Stereotaxy of the Human Brain. Stuttgart, Thieme, 1977.

25 Krauss JK, Loher TJ, Weigel R, Capelle $\mathrm{HH}$, Weber S, Burgunder JM: Chronic stimulation of the globus pallidus internus for treatment of non-dYT1 generalized dystonia and choreoathetosis: 2-year follow up. J Neurosurg 2003;98:785-792.

26 Alterman RL, Miravite J, Weisz D, Shils JL, Bressman SB, Tagliati M: Sixty hertz pallidal deep brain stimulation for primary torsion dystonia. Neurology 2007;69:681-688.
27 Kleiner-Fisman G, Liang GS, Moberg PJ, Ruocco AC, Hurtig HI, Baltuch GH, Jaggi JL, Stern MB: Subthalamic nucleus deep brain stimulation for severe idiopathic dystonia: impact on severity, neuropsychological status, and quality of life. J Neurosurg 2007;107: 29-36.

28 Sun B, Chen S, Zhan S, Le W, Krahl SE: Subthalamic nucleus stimulation for primary dystonia and tardive dystonia. Acta Neurochir Suppl 2007;97:207-214.

29 Ostrem JL, Marks WJ Jr, Volz MM, Heath SL, Starr PA: Pallidal deep brain stimulation in patients with cranial-cervical dystonia (Meige syndrome). Mov Disord 2007;22: 1885-1891

30 Bötzel K, Steude U: First experiences in deep brain stimulation for cervical dystonia (in German). Nervenarzt 2006;77:940-945.

31 Hung SW, Hamani C, Lozano AM, Poon YY, Piboolnurak P, Miyasaki JM, Lang AE, Dostrovsky JO, Hutchison WD, Moro E: Long-term outcome of bilateral pallidal deep brain stimulation for primary cervical dystonia. Neurology 2007;68:457-459.

32 Starr PA, Turner RS, Rau G, Lindsey N, Heath S, Volz M, Ostrem JL, Marks WJ Jr: Microelectrode-guided implantation of deep brain stimulators into the globus pallidus internus for dystonia: techniques, electrode locations, and outcomes. Neurosurg Focus 2004; 17:E4

33 Yianni J, Nandi D, Shad A, Bain P, Gregory R, Aziz T: Increased risk of lead fracture and migration in dystonia compared with other movement disorders following deep brain stimulation. J Clin Neurosci 2004;11:243245.

34 Foncke EM, Schuurman PR, Speelman JD: Suicide after deep brain stimulation of the internal globus pallidus for dystonia. Neurology 2006;66:142-143. 